\section{Effects of Pistacia atlantica (subsp. Mutica) oil extracts on antioxidant activities during experimentally induced cuta- neous wound healing in rats}

\author{
Ahmad Reza Hamidi,1 \\ Aboutorab Tabatabaii Naeini, 1 \\ Nader Tanideh, 2 Saeed Nazifi ${ }^{1}$
}

1Department of Clinical Studies, School of Veterinary Medicine, Shiraz University; 2Department of Stem Cell and Transgenic Technology Research Center, Pharmacology Department, Shiraz University of Medical Sciences, Iran

\section{Abstract}

The fruits of Pistacia atlantica (subsp. muti$\mathrm{ca}$ ) have been used traditionally for the treatment of peptic ulcer, as a mouth freshener and have recently been introduced as a source of antioxidant vegetable oils. The aim of this study was to investigate the antioxidant activity of the gel forms, from $P$. atlantica (subsp. mutica) oil extraction on enzymatic antioxidants in experimental wound created in rat. A square-shaped skin defect $(2 \times 2 \mathrm{~cm})$ was created aseptically by surgical excision at the first thoracic vertebrae. Then animals were randomly allocated in four groups (I, untreated controls; II, topically treated base gel; III, topically treated $5 \%$ gel; IV, topically treated $10 \%$ gel). Blood sampling was accomplished at 3,7 , 10,14 and 21 days post-injury. Samples were collected for measuring antioxidant enzymes activities (superoxide dismutase, catalase and glutathione peroxidase activity in red cells) and lipid peroxidation (plasma malondialdehyde). The data analysis generally evidenced that the activities of the main antioxidant enzymes began to decrease significantly at 7 days after the wound was created in control and base gel groups. This remarkable decline became more evident in the period between 10 to 21 days post injury but increased progressively in P. atlantica (subsp. mutica) treatment groups, especially in gel $10 \%$ treatment group during wound healing. The results of this study suggest that excision of the wound leads to oxidative stress and topical administration of $P$. atlantica (subsp. mutica) gels causes remarkable changes in antioxidant parameter during wound closure (especially gel 10\%) via pro-oxidative, and antioxidant activity can improve oxidative stress.

\section{Introduction}

Cutaneous wound repair is a complex and intricate process which initiates in response to injury that restores the function and integrity of damaged tissue.1,2 The skin is a biological interface with the environment, and is frequently and directly exposed to prooxidative stimuli including chemical oxidants, ultraviolet and visible irradiation, which are known to promote the generation of reactive oxygen species (ROSs) and lipid peroxides.3,4 Particularly large amounts of ROS are produced in wounded and inflamed tissue by NADPH oxidase, an enzyme complex expressed at specifically high levels by inflammatory cells. ${ }^{5,6}$ ROSs are produced in response to cutaneous injury, which further impede the healing process by causing damage to cellular membranes, DNA, proteins and lipids as well.7 Further, elevated lipid peroxide levels have also been demonstrated in certain inflammatory skin lesions such as traumatic wounds and radiation dermatitis. ${ }^{8}$

P. atlantica (subsp. mutica) trees grow in large populations and cover an area more than $1,200,000$ ha mainly in the western, central and eastern parts of Iran. The fruits of $P$. atlantica (subsp. mutica), which have been used traditionally for the treatment of peptic ulcer and as a mouth freshener, ${ }^{9}$ are called Bene in Iran and are used by the natives as food after grinding and mixing with other ingredients. 10 Bene hull oil (BHO) as a new source of highly stable and antioxidative vegetable oils has recently been introduced to the world. ${ }^{10}$ They are round to oval, somewhat flat, and $0.5-0.7 \mathrm{~cm}$ in diameter. Their wooden hard shell is covered with a rather dry hull which could be easily removed by pressing between the fingers. This soft hull is dark green in color, comprises $24 \%$ of the whole fruit $(25 \%$ kernel and $51 \%$ hard shell) and yields up to $30 \%$ oil. $10-12$

P. atlantica (subsp. mutica) oil contains saturated fatty acids [mainly palmitic acid in BHO (26.45\%) and bene kernel oil (BKO) (13.15\%)], mono unsaturated fatty acid [palmitoleic acid in BHO (13.38\%) and BKO (1.78\%); and oleic acid ranges from 52 to $61 \%]$, and the lowest percentage of polyunsaturated fatty acids (mainly linoleic acid in BHO (6.60\%) and BKO (33.00\%)]. The BHO contains about $6.5 \%$ unsaponifiable matter (USM) which is considered to be the highest content amongst all common vegetable oils. ${ }^{13}$ The tocopherols and tocotrienols are the major constituents (48\%) of the USM. ${ }^{13}$ They display antioxidant properties and are active as vitamin E, which makes them particularly important for human health. ${ }^{13}$

The second major constituents of the USM with a total yield of about $37 \%$ are the triter-
Correspondence: Saeed Nazifi, Department of Clinical Studies, School of Veterinary Medicine, Shiraz University of Fars, Shiraz, Iran. Tel.: +98.711.2286950 - Fax: +98.711 .2286940 . E-mail: nazifi@shirazu.ac.ir

Key words: Pistacia atlantica; antioxidant; wound healing; rat.

Acknowledgments: this research is part of $\mathrm{Dr}$ Hamidi's thesis and he would like to thank the Research Council of Shiraz University and School of Veterinary Medicine, Shiraz University for financial and technical support of this study (Grant No. 71-GR-VT-5).

Contributions: the authors contributed equally.

Conflict of interest: the authors declare no potential conflict of interest.

Received for publication: 13 October 2014. Revision received: 13 December 2014. Accepted for publication: 16 December 2014

This work is licensed under a Creative Commons Attribution NonCommercial 3.0 License (CC BYNC 3.0).

(C) Copyright A.R. Hamidi et al., 2015 Licensee PAGEPress srl, Italy

Veterinary Science Development 2015; 5:5672 doi:10.4081/vsd.2015.5672

penic compounds (sterolic types and dialcoholic ones). ${ }^{13}$ These steroidal phytochemicals contained in vegetable oils are hypocholesterolemic and may also be potent antioxidants. The sterol composition of the BHO consists of seven compounds with b-sitosterol as the major constituent $(746.1 \mathrm{mg} / \mathrm{kg})$.

Bene kernel oil contains $817.92 \mathrm{mg} / \mathrm{kg}$ of total tocopherol and $213.47 \mathrm{mg} / \mathrm{kg}$ of the total phenolic content respectively. ${ }^{14}$ Regarding the fatty acid composition and total tocopherols and phenolic compounds determined, the oil extracted from the kernel of $P$. atlantica (subsp. mutica) is considered as one of the most oxidatively stable vegetable oils in the world. ${ }^{14}$ Both tocopherols and phenolic compounds are very important natural antioxidants for the stabilization of unsaturated fatty acids and provide an effective protection against oxidative stress in the human body. ${ }^{15,16}$ Tocopherols have antioxidant properties and they are active as vitamin $\mathrm{E}$, which makes them particularly important for human health.10 Antioxidants have been shown to promote wound healing. $7,17,18$ Their levels have been shown to be depleted in the healing of cutaneous wounds in normal subjects, which either partially or completely recover following healing. 19 Therefore, the aim of our work was to evaluate the effect of the $P$. atlantica's gels extraction on 
enzymatic antioxidants in experimental wound created in rat.

\section{Materials and Methods}

\section{Animals}

One hundred Sprague dawley male rats, weighing $200 \pm 20 \mathrm{~g}$ were used in the experiment. The animals were kept in standard individual cages, at constant temperature (22$24^{\circ} \mathrm{C}$ ) in animal lab of Shiraz University, with 12-hour light and dark cycles. They were fed a standard rat chow, and had free access to food and water (ad libitium).

\section{Injury induction}

The animals were anaesthetized by intramuscular injection of $10 \mathrm{mg} / \mathrm{kg}$ xylazine $\mathrm{HCl}$ (Xylazine 2\%; Alfasan) as premedication, and $90 \mathrm{mg} / \mathrm{kg}$ ketamine $\mathrm{HCl}$ (Ketamine 10\%; Alfasan) for anesthesia. A square-shaped skin defect $(2 \times 2 \mathrm{~cm})$ was created aseptically by surgical incision at the first thoracic vertebrae and $1 \mathrm{~cm}$ proximal to the first lumbar vertebrae. This method of wound induction has been used previously to investigate cutaneous wound healing in rats. ${ }^{20}$

\section{Oil extraction}

Fresh $P$ atlantica (subsp. mutica) fruit were purchased from a retail food store (Chehel giah store, Ghasre Dasht Street, Shiraz, Iran) in March 2012. After drying in the shade, $P$ atlantica (subsp. mutica) fruit were ground to powder in a grinder. The powders were extracted with n- hexane (1: $4 \mathrm{wt} / \mathrm{vol})$ by agitation in a dark place at ambient temperature for $48 \mathrm{~h}$. The solvent was evaporated in vacuo at $40^{\circ} \mathrm{C}$ to dryness. ${ }^{21}$

\section{Preparation of the gel}

To prepare the gel $1 \mathrm{~g}$ carbopol (polymers of high molecular weight of acrylic acid cross linked with a polyalkenyl polyether and flexibility to develop products with a wide range of flow and rheological properties) was added to 95 cc distilled water ( $5 \%$ gel), and $1 \mathrm{~g}$ to $90 \mathrm{cc}$ distilled water (10\% gel); after 4 or $5 \mathrm{~h}$, all carbopol powder was dissolved and sodium hydroxide was added to make the gel base. Finally, $5 \mathrm{~g}$ (5\% gel) and $10 \mathrm{~g}$ (10\% gel) oil extract were added to the gel base and used for all experiments.

\section{Experimental design}

After wound creation, the animals were divided into four groups of twenty-five rats and each group was divided in five subgroups and, at this time, treatment was initiated with specific gels.

Group I, untreated controls; Group II, topi- cally treated base gel; Group III, topically treated $5 \%$ gel; Group IV, topically treated $10 \%$ gel. At this time rats were treated with these gels.

\section{Animal ethics}

This experiment was performed under the approval of the State Committee on Animal Ethics, Shiraz University, Shiraz, Iran. Also, the recommendations of the European Council Directive (86/609/EC) of November 24, 1986, regarding the protection of animals used for experimental purposes were considered.

\section{Blood sample preparation}

Blood sampling was accomplished at 3,7 , 10, 14 and 21 days post-injury. Samples were collected from the heart into tubes containing heparin for measuring antioxidant enzymes activities [superoxide dismutase (SOD), catalase and glutathione peroxidase (GPx) activity in red cells] and lipid peroxidation [plasma malondialdehyde (MDA)] within 5-6 h after blood sampling.

\section{Hemolysate preparation}

Whole blood $(0.5 \mathrm{~mL})$ was centrifuged at 700 $\mathrm{g}$ for $15 \mathrm{~min}$. The plasma was aspirated off, and the erythrocyte pellet was washed three times with normal saline solution, then, distilled water was slowly added up to $2 \mathrm{~mL}$. The biochemical tests were performed immediately after preparing the hemolysate.

\section{Biochemical assays}

The activities of superoxide dismutase and glutathione peroxidase

Superoxide dismutase activity was measured with a commercial kit (RANSOD kit, Randox Com, UK). According to the manufacturer's manual, $0.5 \mathrm{~mL}$ of whole blood was centrifuged for 10 minutes at $700 \mathrm{~g}$ and the plasma was aspirated off. The erythrocytes were washed four times with $3 \mathrm{~mL}$ of $0.9 \% \mathrm{NaCl}$ solution and were centrifuged each time to separate the supernatant. The washed erythrocytes were diluted to $2 \mathrm{~mL}$ with cold redistilled water. After thorough mixing the lysate was diluted with $0.01 \mathrm{~mol} / \mathrm{L}$ phosphate buffer $(\mathrm{pH}=7)$ with a final dilution factor of 200 . The reagents were then added to the diluted samples. In this method, xanthine and xanthine oxidase are employed to generate superoxide radicals, which react with 2-(4-iodophenyl)-3(4-nitrophenol)-5-phenyltetrazolium chloride (INT) to form a red formazan dye. The SOD activity in hemolysate was determined by the degree of inhibition of this reaction as one unit of SOD corresponded to $50 \%$ inhibition of INT reduction under assay condition. Finally, the enzyme activity was expressed as units/g of hemoglobin.

GPx activity was measured by a commercial kit (RANSEL kit, Randox Com, UK) based on the method of Paglia and Valentine.22 According to the manual, $0.05 \mathrm{~mL}$ of whole blood was diluted and incubated with $3 \mathrm{ml}$ of a diluting agent to form the hemolysate. The GPx present in the hemolysate catalyses the oxidation of glutathione (GSH) by cumene hydroperoxide. In the presence of glutathione reductase and $\mathrm{NADPH}$, the oxidized glutathione is immediately converted to the reduced form with a concomitant oxidation of $\mathrm{NADPH}$ to NADP+. The absorbance was measured at $340 \mathrm{~nm}$ and the enzyme activity was expressed as units/g of hemoglobin.

\section{Catalase assay}

Tissue catalase activity was assayed spectrophotometrically by monitoring the decomposition of $\mathrm{H}_{2} \mathrm{O}_{2}$ using the procedure of Aebi. ${ }^{23}$ Briefly, $0.5 \mathrm{~mL}$ of $30 \mathrm{mmol} / \mathrm{L} \mathrm{H}_{2} \mathrm{O}_{2}$ solution in $50 \mathrm{mmol} / \mathrm{L}$ phosphate buffer $(\mathrm{pH}=7.0), 1 \mathrm{~mL}$ of 1: 10 diluted erythrocyte lysates was added and the consumption of $\mathrm{H}_{2} \mathrm{O}_{2}$ was followed spectrophotometrically at $240 \mathrm{~nm}$ for $2 \mathrm{~min}$ at $25^{\circ} \mathrm{C}$. The molar extinction coefficient was 43.6 $\mathrm{L} / \mathrm{mol}$ per $\mathrm{cm}$ for $\mathrm{H}_{2} \mathrm{O}_{2}$. Catalase activity was expressed as the unit that is defined as $\mu \mathrm{mol}$ $\mathrm{H}_{2} \mathrm{O}_{2}$ consumed/min per gram hemoglobin.

\section{Measurement of malondialdehyde}

To evaluate lipid peroxidation in erythrocytes, a modified HPLC method based on the reaction of malondialdehyde (MDA) with thiobarbituric acid (TBA) to form a colored MDATBA adduct was used.24 Erythrocytes were washed three times with phosphate-buffered saline. Then, $40 \mu \mathrm{L}$ of sample was diluted with $100 \mu \mathrm{L}$ of $\mathrm{H}_{2} \mathrm{O}$ and mixed with $20 \mu \mathrm{L}$ of 2.8 $\mathrm{mmol} / \mathrm{L}$ butylated hydroxytoluene (BHT) in ethanol, $40 \mu \mathrm{L}$ of $81 \mathrm{~g} / \mathrm{L}$ sodium dodecyl sulfate and $600 \mu \mathrm{L}$ of TBA reagent $(8 \mathrm{~g} / \mathrm{L}$ TBA diluted 1:1 with $200 \mathrm{ml} / \mathrm{L}$ acetic acid adjusted to $\mathrm{pH} 3.5$ with $\mathrm{NaOH})$. The mixture was immediately heated $\left(60 \mathrm{~min}\right.$ at $\left.95^{\circ} \mathrm{C}\right)$ and cooled with running water; $200 \mu \mathrm{L}$ of $\mathrm{H}_{2} \mathrm{O}$ and $1000 \mu \mathrm{L}$ of butanol-pyridine $(15: 1, \mathrm{v} / \mathrm{v})$ were then added. After vigorous mixing, the organic layer was separated by centrifugation ( $3 \mathrm{~min}$ at $16,000 \mathrm{~g}$ ). The supernatant was analyzed on a UV-visible spectrophotometer fitted with an $80 \mu \mathrm{L}$ flow cell. The absorbance was measured at $532 \mathrm{~nm}$ (the mobile phase consisted of $300 \mathrm{~mL} / \mathrm{L}$ methanol in $50 \mathrm{mmol} / \mathrm{L}$ potassium dihydrogen phosphate buffer, pH 7.0). 1, 1, 3, 3-tetraethoxypropane was used as a standard, and MDA-TBA reactive substances values were expressed as MDA nano-moles per grams of hemoglobin (nmol/g $\mathrm{Hb}$ ). The HPLC system was comprised of a solvent delivery pump (JASCO 980-PU, Tokyo, Japan), a reversed-phase column (Luna C18, $250 \times 4.6 \mathrm{~mm}$, Phenomenex, CA, USA), and a UVVis detector (Jasco, UV-975, Tokyo, Japan) operated at $532 \mathrm{~nm}$. 


\section{Statistical analysis}

The differences between means of measured parameters between groups in different times of blood sampling were analyzed by Multivariate analysis of variance (ANOVA). Differences between means were estimated using Tukey test. The values are expressed as mean \pm standard error of mean (SEM). All data were analyzed with SPSS/17 software. $\mathrm{P}<0.05$ was considered significant.

\section{Results}

Our data revealed remarkable changes in antioxidant-oxidant related parameters in experimental wound during a period of 21 days after topical $P$. atlantica (subsp. mutica) gels administration. These changes are presented in Tables 1-4.

As shown, the data analysis generally evidenced that the activities of the main erythrocyte antioxidant enzymes began to decrease significantly at 7 days after wound creation in control and base gel groups. This remarkable decline became more evident in a period between 10 and 21days post injury but increased progressively in $P$. atlantica (subsp. mutica) treatment groups, especially in $10 \%$ gel treatment group during wound healing.

Table 1 , shows the mean \pm SE of SOD activity in red cells of control, base gel, $P$. atlantica (subsp. mutica) gel 5\% and $P$ atlantica (subsp. mutica) $10 \%$ gel treated rats. There was no significant difference in the SOD activities of control and base gel treated rats, which remained relatively constant throughout the healing period. $10 \%$ gel treated group showed significant increase in SOD levels 3 days after administration compared to the control and base gel group $(\mathrm{P}<0.0001)$, however, gel $5 \%$ treated group increased SOD level significantly 10 days after administration compared to the control and base gel groups.

According to our data (Tables 2 and 3), the activity of GPx and CAT was affected significantly at an earlier time in P. atlantica (subsp. mutica) treated groups (especially in gel 10\%) compared to control and base gel treated groups during wound repair.

In contrast to the antioxidant parameters, the serum levels of MDA (Table 4) in blood samples revealed remarkable increases in the control and base gel treatment animals but decreased significantly in $P$. atlantica (subsp. mutica) treated groups, especially in gel $10 \%$ treated group during wound repair.

\section{Discussion}

The result of the present study showed that topical administration of $P$. atlantica (subsp. mutica) gels causes remarkable changes in antioxidant parameter during wound closure, especially in gel $10 \%$ during the first 3 days of the wound healing.

The balance between free radicals and antioxidants may disrupt in many diseases. This disruption may be attributed to a number of factors such as the inability of the cells to produce sufficient amounts of antioxidants or the excess production of ROS.25 Wounding is another condition that results in a decrease in antioxidants. ${ }^{19}$ Guo and DiPietro suggested vitamin $\mathrm{E}$, an anti-oxidant, maintain and stabilize cellular membrane integrity by providing protection against destruction by oxidation. ${ }^{26}$ Vitamin E also has anti-inflammatory properties and has been suggested to have a role in decreasing excess scar formation in chronic wounds. Another study suggested vitamin E,

Table 1. Mean \pm standard error of changes in superoxide dismutase activities of Bene oil gels compared with control and base gel on different days post injury.

\begin{tabular}{lcccc} 
Days post injury & Control & Base gel & $5 \%$ Bene gel & $10 \%$ Bene gel \\
3 & $347 \pm 3.39 \mathrm{~d}$ & $346 \pm 3.43^{\mathrm{d}}$ & $360 \pm 2.74$ & $369 \pm 2.92^{\mathrm{ab}}$ \\
7 & $346 \pm 1.87 \mathrm{~d}$ & $347 \pm 2.30 \mathrm{~d}$ & $362 \pm 3.39$ & $372 \pm 3 \mathrm{ab}$ \\
\hline 10 & $329 \pm 1.87 \mathrm{~cd}$ & $328 \pm 1.72 \mathrm{~cd}$ & $399 \pm 5.57 \mathrm{ab}$ & $412 \pm 4.06 \mathrm{ab}$ \\
14 & $322 \pm 2.55 \mathrm{~cd}$ & $321 \pm 2.56 \mathrm{~cd}$ & $409 \pm 4.58 \mathrm{ab}$ & $422 \pm 4.36 \mathrm{ab}$ \\
\hline 21 & $321 \pm 3.67 \mathrm{~cd}$ & $319 \pm 3.44 \mathrm{~cd}$ & $430 \pm 6.32 \mathrm{ab}$ & $445 \pm 2.74$ \\
\hline abDifferent letters (a=control, $\mathrm{b}=$ base gel, $\mathrm{c}=5 \%$ Bene oil gel, $\mathrm{d}=10 \%$ Bene oil gel) represent significant differences for that variable between
\end{tabular}
the associated groups, at different days.

Table 2. Mean \pm standard error of changes in plasma glutathione peroxidase activities of Bene oil gels compared with control and base gel on different days post injury.

\begin{tabular}{lcccc} 
Days post injury & Control & Base gel & $5 \%$ Bene gel & $10 \%$ Bene gel \\
3 & $461 \pm 1.87 \mathrm{~d}$ & $462 \pm 1.50 \mathrm{~d}$ & $474 \pm 2.45$ & $482 \pm 2 \mathrm{ab}$ \\
7 & $458 \pm 2.55 \mathrm{~d}$ & $459 \pm 2.46 \mathrm{~d}$ & $476 \pm 2.92$ & $487 \pm 2.55 \mathrm{ab}$ \\
\hline 10 & $446 \pm 1.87 \mathrm{dc}$ & $445 \pm 3.34 \mathrm{~cd}$ & $507 \pm 4.36 \mathrm{ab}$ & $525 \pm 4.74 \mathrm{ab}$ \\
14 & $436 \pm 1.87 \mathrm{dc}$ & $436 \pm 2.08 \mathrm{~cd}$ & $514 \pm 6 \mathrm{abd}$ & $541 \pm 3.67 \mathrm{abc}$ \\
\hline 21 & $429 \pm 2.92 \mathrm{dc}$ & $427 \pm 2.77 \mathrm{~cd}$ & $528 \pm 8 \mathrm{abd}$ & $552 \pm 2.55 \mathrm{abc}$ \\
\hline
\end{tabular}

Different letters ( $a=$ control, $b=$ base gel, $c=5 \%$ Bene oil gel, $d=10 \%$ Bene oil gel) represent significant differences for that variable between the associated groups, at different days.

Table 3. Mean \pm standard error of changes in catalase activities of Bene oil gels compared with control and base gel on different days post injury.

\begin{tabular}{lcccc} 
Days post injury & Control & Base gel & $5 \%$ Bene gel & $10 \%$ Bene gel \\
3 & $1811 \pm 5.1^{\mathrm{d}}$ & $1813 \pm 4.79 \mathrm{~d}$ & $1898 \pm 11.58$ & $1922 \pm 8.6^{\mathrm{ab}}$ \\
7 & $1810 \pm 4.47$ & $1811 \pm 3.47$ & $1898 \pm 8.6$ & $1915 \pm 7.07$ \\
\hline 10 & $1758 \pm 17.72^{\mathrm{cd}}$ & $1754 \pm 16^{\mathrm{cd}}$ & $2008 \pm 23.54 \mathrm{ab}$ & $2063 \pm 21.42 \mathrm{ab}$ \\
14 & $1650 \pm 22.36^{\mathrm{cd}}$ & $1666 \pm 20.15 \mathrm{~cd}$ & $2054 \pm 38.03 \mathrm{ab}$ & $2154 \pm 37.5^{\mathrm{ab}}$ \\
\hline 21 & $1580 \pm 25.5 \mathrm{~cd}$ & $1575 \pm 27.39 \mathrm{~cd}$ & $2101 \pm 21.3 \mathrm{abd}$ & $2212 \pm 33.82 \mathrm{abc}$ \\
\hline
\end{tabular}

Different letters ( $\mathrm{a}=$ control, $\mathrm{b}=$ base gel, $\mathrm{c}=5 \%$ Bene oil gel, $\mathrm{d}=10 \%$ Bene oil gel) represent significant differences for that variable between the associated groups, at different days.

Table 4. Mean \pm standard error of changes in malondialdehyde of Bene oil gels compared with control and base gel on different days post injury.

\begin{tabular}{lcccc} 
Days post injury & Control & Base gel & $5 \%$ Bene gel & $10 \%$ Bene gel \\
3 & $14.7 \pm 0.25$ & $14.72 \pm 0.29$ & $13.70 \pm 0.25$ & $13.94 \pm 0.26$ \\
7 & $14.8 \pm 0.25^{\mathrm{d}}$ & $14.94 \pm 0.26^{\mathrm{d}}$ & $14.20 \pm 0.12$ & $13.30 \pm 0.07 \mathrm{ab}$ \\
\hline 10 & $15.8 \pm 0.25^{\mathrm{cd}}$ & $15.84 \pm 0.2^{\mathrm{cd}}$ & $12.60 \pm 0.19 \mathrm{ab}$ & $12.14 \pm 0.15^{\mathrm{ab}}$ \\
14 & $16.1 \pm 0.24 \mathrm{~cd}$ & $16.12 \pm 0.25^{\mathrm{cd}}$ & $11.40 \pm 0.19 \mathrm{ab}$ & $11.28 \pm 0.16^{\mathrm{ab}}$ \\
\hline 21 & $17.1 \pm 0.19 \mathrm{~cd}$ & $17.30 \pm 0.18 \mathrm{~cd}$ & $10.60 \pm 0.19 \mathrm{ab}$ & $10.14 \pm 0.36^{\mathrm{ab}}$ \\
\hline
\end{tabular}

Different letters ( $a=$ control, $b=$ base gel, $c=5 \%$ Bene oil gel, $d=10 \%$ Bene oil gel) represent significant differences for that variable between the associated groups, at different days. 
the term for a group of tocopherols and tocotrienols, is the major lipid soluble antioxidant in skin; it protects cell membranes from peroxidative damage and the deleterious effects of free radicals. 27,28

Also in agreement with our finding, Schäfer and Sabine Werner suggested compounds present in food, such as vitamins E and C (ascorbic acid), carotinoids, and phenolic compounds have antioxidant properties. ${ }^{29}$ Another study by Shukla et al. ${ }^{19}$ showed in acute rodent wounds, the levels of vitamin E, ascorbate and glutathione decreased by $60-70 \%$ as compared to normal skin and only the levels of glutathione recovered completely within 14 days after wounding. ${ }^{19}$ It has also been shown that strongly reduced levels of glutathione, Vitamin $\mathrm{E}$ and ascorbate were observed in normal and, in particular, in wounded skin of immunosuppressed rats as compared to immunocompetent animals. ${ }^{30}$

Consistent with other findings, palm vitamin $\mathrm{E}$ extract, which contains a mixture of $60 \%$ tocotrienol and $40 \%$ tocopherol, enhances wound healing in diabetic rats and increases the activity of the GPx enzyme. ${ }^{31}$ Musalmah $e t$ $a l .{ }^{32}$ showed that basal GPx levels were lower in diabetic rats, confirming the earlier reports. ${ }^{31,33,34}$ Musalmah et al. 32 showed that daily oral supplementation with $\alpha$-tocopherol increased the level of SOD and GPx. ${ }^{32}$ These enzymes scavenge free radicals and prevent oxidative damage. ${ }^{32}$

Schäfer and Werner suggested SOD activity was reduced upon skin injury in rats, and the activities did not fully recover within 14 days. ${ }^{29}$ Panchatcharam et al. ${ }^{35}$ showed that antioxidant treatment, using curcumin, resulted in increased levels of SODs and also of catalase and glutathione peroxidase activities at the wound site. To determine the function of SODs in wound repair, ischemic rat wounds were treated with recombinant SOD. Interestingly, wound breaking strength was increased and wound edema was reduced..$^{36}$ In another study, hydrogels of carboxymethyl cellulose were prepared and loaded with bovine SOD1. When applied to rat wounds, the SOD-hydrogel was able to enhance the wound-healing rate. 37

Similar to our study, Shukla et al. ${ }^{19}$ showed that activities of catalase and glutathione peroxidase decreased upon skin injury in rats, possibly due to ROS-mediated inactivation. This was also observed in immunocompromised rats, where catalase and glutathione peroxidase activities declined within 2 days after skin injury. ${ }^{30}$

Consistent with our findings, Musalmah et al. 32 showed that Plasma MDA levels were increased in untreated diabetic rats. This probably reflects the increase in lipid oxidation due to either increased production of free oxidative radicals, ${ }^{38}$ or decreased antioxidant defense mechanisms or both. ${ }^{31,34,39}$ They showed sup- plementation with $\alpha$-tocopherol decreased the level of MDA in both the normal and diabetic groups, confirming the role of $\alpha$-tocopherol as a powerful antioxidant. ${ }^{32}$ Another finding showed Vitamin E or $\alpha$-tocopherol supplementation reduced the levels of lipid peroxides in the wound tissue of diabetic rats, and the wound healing process was enhanced, especially in the Vitamin E-treated animals. ${ }^{40}$ Several findings suggest that phytosterols, such as b-sitosterol are responsible, at least in part, for preventive effects on the development of diseases due to ROS.41 Moreover, Yoshida and Niki reported the antioxidant effects of the phytosterols b-sitosterol, stigmasterol, and campesterol, against lipid peroxidation. 42

\section{Conclusions}

In conclusion, the results of this study suggest that excision of the wound leads to oxidative stress and topical administration of $P$. atlantica gels causes remarkable changes in antioxidant parameter during wound closure (especially gel 10\%) via pro-oxidative and antioxidant activity which can improve oxidative stress.

\section{References}

1. Clark R. Biology of dermal wound repair. Dermatol Clin 1993;11:647-66.

2. Abbasian B, Azizi S, Esmaeili A. Effects of rat's licking behavior on cutaneous wound healing. Iran J Basic Med Sci 2010;13:2427.

3. Guo Q, Packer L. Ascorbate dependent recycling of vitamin $\mathrm{E}$ homologue trolox by dihydrolipoate and glutathione in murine skin homogenate. Free Radic Biol Med 2000;29:368-74.

4. Picardo M , Passi S. Skin immune system. New York: CRC Press; 1997. pp 207-226.

5. Bedard K, Krause K. The nox family of rosgenerating nadph oxidases: physiology and pathophysiology. Physiol Rev 2007;87: 245-313.

6. Darr D, Fridovich I. Free radicals in cutaneous biology. J Investig Dermatol 1994;102:671-5.

7. Martin A. The use of antioxidants in healing. Dermatol Surg 1996;22:156-60.

8. Niwa Y, Kanoh T, Sakane T, et al. The ratio of lipid peroxides to superoxide dismutase activity in the skin lesions of patients with severe skin disease: an accurate prognostic indicator. Life Sci 1987;40:921-7.

9. Abdel-Rahman HY, Youssef AM. Mastich as an antioxidant. J Am Oil Chem Soc 1975;52:423.

10. Farhoosh R, Haddad Khodaparast M, 25. Abd Ellah M. Involvement of free radicals
Sharif A. Bene hull oil as a highly stable and antioxidative vegetable oil. Eur J Lipid Sci Technol 2009;111:1259-65.

11. Daneshrad A, Aynehchi Y. Chemical studies of the oil from pistacia nuts growing wild in Iran. J Am Oil Chem Soc 1980;57:248-9.

12. Farhoosh R, Tavakoli J, Haddad Khodaparast M. Chemical composition and oxidative stability of Kernel oils from two current subspecies of Pistacia atlantica in Iran. J Am Oil Chem Soc 2008;85:7239.

13. Farhoosh R, Hossein M, Tavassoli-Kafrani MH, Sharif A. Antioxidant activity of the fractions separated from the unsaponifiable matter of bene hull oil. Food Chem 2011;126:583-9.

14. Sharayei P, Farhoosh R, Poorazrang H, Haddad Khodaparast M. Effect of bene Kernel oil on the frying stability of Canola oil. J Am Oil Chem Soc 2010;88:647-54.

15. Lampi AM, Kajata L, Kamal-Eldin A, Piironen V. Antioxidant activities of a-and g-tocopherols in the oxidation of rapeseed oil triacrylglycerols. J Am Oil Chem Soc 1999;76:749-55.

16. Papas AM. Antioxidant status, diet, nutrition and health. Boca Raton: CRC Press; 1998.

17. Silaeva S, Guliaeva N, Khatsernova B, et al. Effects of 4-methyluracil and carnosine on healing of skin wounds in rats. BiolEksp Biol Med 1990;109:180-2.

18. Slater T. Free radical mechanisms in tissue injury. Biochem J 1984;222:1-5.

19. Shukla A, Rasik A, Patnaik G. Depletion of reduced glutathione, ascorbic acid, vitamin $\mathrm{E}$ and antioxidant defence enzymes in a healing cutaneous wound. Free Radic Res 1997;269:93-101.

20. Oryan A, Zaker R. Effects of topical application of honey on cutaneous wound healing in rabbits. Zentralbl Veterinarmed A 1998;45:181-8.

21. Farhoosh R, Tavassoli-Kafrani MH. Frying performance of the hull oil unsaponifiable matter of Pistacia atlantica subsp. mutica. Eur J Lipid Sci Technol 2010;112:343-8.

22. Paglia D, Valentine W. Studies on the quantitative and qualitative characterization of erythrocyte glutathione peroxidase. J Lab Clin Med 1967;70:158-69.

23. Aebi HE. Catalase. In: Bergmeyer HU, ed. Methods of enzymatic analysis. 3 ed. Weinheim: Verlag Chemie; 1983. pp 273 286.

24. Lykkesfeldt J. Determination of malondialdehyde as dithiobarbituric acid adduct in biological samples by HPLC with fluorescence detection: comparison with ultraviolet-visible spectrophotometry. Clin Chem 2001;47:1725-7. 
in animal diseases. Comparative Clin Pathol 2010;19:615-9.

26. Guo S, DiPietro LA. Factors affecting wound healing. J Dent Res 2010;89:219-29.

27. Rojas AI , Phillips TJ. Patients with chronic leg ulcers show diminished levels of vitamins $\mathrm{A}$ and $\mathrm{E}$, carotenes, and zinc. Dermatol Surg 1999;25:601-4.

28. Suleyman H, Gumustekin K, Taysi S, et al. Beneficial effects of hippophae rhamnoides L. on nicotine induced oxidative stress in rat blood compared with vitamin E. Biol Pharm Bull 2002;25:1133-6.

29. Schäfer M, Werner S. Oxidative stress in normal and impaired wound repair. Pharmacol Res 2008;58:165-71.

30. Gupta A, Singh R, Raghubir R. Antioxidant status during cutaneous wound healing in immunocompromised rats. Mol Cell Biochem 2002;241:1-7.

31. Musalmah M, Fairuz A, Gapor M, Wan Ngah WZ. Effect of palm vitee on wound healing in normal and diabetic rats. Malaysian J Biochem Mol Biol 2001;6:34-9. 32. Musalmah M, Fairuz AH, Gapor MT, Wan
Ngah WZ. Effect of vitamin E on plasma malondialdehyde, antioxidant enzyme levels and the rates of wound closures during wound healing in normal and diabetic rats. Asia Pac J Clin Nutr 2002;11:448-51.

33. Cunningham J, Ellis S, McVeigh $\mathrm{K}$, et al. Reduced mononuclear leukocyte ascorbic acid content in adults with insulin-dependent diabetes mellitus consuming adequate dietary vitamin C. Metabolism 1991;40:146-9.

34. Jones A, Winkles J, Jennings $P$, et al. Serum antioxidant activity in diabetes mellitus. Diabetes Res 1988;7:89-92.

35. Panchatcharam M, Miriyala S, Gayathri V, Suguna L. Curcumin improves wound healing by modulating collagen and decreasing reactive oxygen species. Mol Cell Biochem 2006;290:87-96.

36. Senel 0, Cetinkale 0, Ozbay G, et al. Oxygen free radicals impair wound healing in ischemic rat skin. Ann Plast Surg 1997;39:516-23.

37. Chiumiento A, Lamponi S, Barbucci R, et al. Immobilizing $\mathrm{Cu}, \mathrm{Zn}$-superoxide dis- mutase in hydrogels of carboxymethylcellulose improves its stability and wound healing properties. Biochemistry (Mosc) 2006;71:1324-8.

38. Baynes J. Role of oxidative stress in the development of complications in diabetes. Diabetes 1991;40:405-12.

39. Gallou G, Ruelland A, Legras B, et al. Plasma malondialdehyde in type 1 and 2 diabetic patients. Clinica Chimica Acta 1993;214:227-34.

40. Musalmah M, Nizrana M, Fairuz A, et al. Comparative effects of palm vitamin e and alpha-tocopherol on healing and wound tissue antioxidant enzyme levels in diabetic rats. Lipids 2005;40:575-80.

41. Vivacons M, Moreno JJ. Beta-sitosterol modulates antioxidant enzyme response in RAW 264.7 macrophages. Free Rad Biol Med 2005;39:91-7.

42. Yoshida Y, Niki E. Antioxidant effects of phytosterol and its components. J Nutr Sci Vitaminol 2003;49:277-80. 